\title{
Dielectric Behaviour of Pure and Dye Doped Nematic Liquid Crystal BKS/B07
}

\author{
Rajiv Manohar $^{2}$, Shashwati Manohar ${ }^{3}$, V. S. Chandel ${ }^{1}$ \\ ${ }^{1}$ Department of Physics, Integral University, Lucknow, India; ${ }^{2}$ Department of Physics, Lucknow University, Lucknow, India; \\ ${ }^{3}$ Department of Physics, RML Awadh University, Faizabad, India. \\ E-mail: rajiv.manohar@gmail.com
}

Received July $26^{\text {th }}, 2010$; revised September $4^{\text {th }}, 2010$; accepted May $30^{\text {th }}, 2011$.

\begin{abstract}
The dielectric properties of pure nematic liquid crystal (BKS/B07) and dye doped (Rhodamine B and Anthraquinone) nematic liquid crystal have been investigated in a wide frequency range of $1 \mathrm{kHz}$ to $10 \mathrm{MHz}$ through the dielectric spectroscopic method at varying temperature. In addition to this optical transmittance and textures of the samples have also been observed with a polarizing microscope.
\end{abstract}

Keywords: Liquid Crystals, Dielectric Properties

\section{Introduction}

Organic molecules and liquid crystals (LC) are well established materials for photonic and non-linear optical device applications because of their optical non linearity and very rapid optical response [1]. In a mixture of LC and dichroic dye the action of an electric field influences the collective orientation of the LC molecules and that of the dye molecules. This phenomenon is called Guest-host interaction. Dyes have been widely used as guest additives in optical materials to develop novel optoelectronic devices. Again it is well established that the presence of dye molecules in the liquid crystal host influences many properties of the pure liquid crystals. The Effect of dye on dielectric properties of liquid crystals has been investigated earlier by some groups [2,3]. The change in nonlinear refractive index and birefringence of dye doped nematic mixture has been investigated by A. Jafari et al.[4]. It has also experimentally proved that doping a small amount of dye decreases the required threshold of molecular reorientation further in LC materials [5]. Temperature dependence of direction reorientation of dye doped nematic liquid crystal has been studied by Esteves et al. [6]. Voigot et al. have studied emission of circularly polarized light in dye based chiral nematic liquid crystals [7]. Thermal non-linearity of dye doped nematic liquid crystals have been reported by Henninot et al. [8], while photovoltaic effect in liquid crystal cells containing dyes have been studied by Sato et al. [9]. Mustafa Okutan et al. have studies refractive index dis- persion and electrical properties of carbon nono -balls' doped nematic liquid crystal [10].

Most of the efforts are aimed on the electro-optical characterization of LC $[11,12]$, but no serious work have been done in understanding the dielectric properties of dye doped liquid crystals. In the recent years few articles have been published by Mustafa Okutan et. al., S. Ozder et al. [13-15].The dielectric spectroscopy technique has also been used by many workers for the study of LCs in different phases, as the technique provides very accurate data about the material under investigation. Therefore, the present paper is an effort to investigate the effect of dye on dielectric property of liquid crystal host molecules. In order to confirm the changes occurred in phase transition temperature as a result of dye mixing optical transmittance measurement of the sample have also been done.

\section{Materials}

The liquid crystal sample used for the present investigation was used without further purification. The transition schemes of the pure sample as well as dye doped samples are as follows: (Figure 1)

All dyes used in the experiment were obtained from Thomas Beker. Their chemical names and compositions are given below. (Figure 2)

\section{Experimental}

The pure sample was used as such and the dye doped 


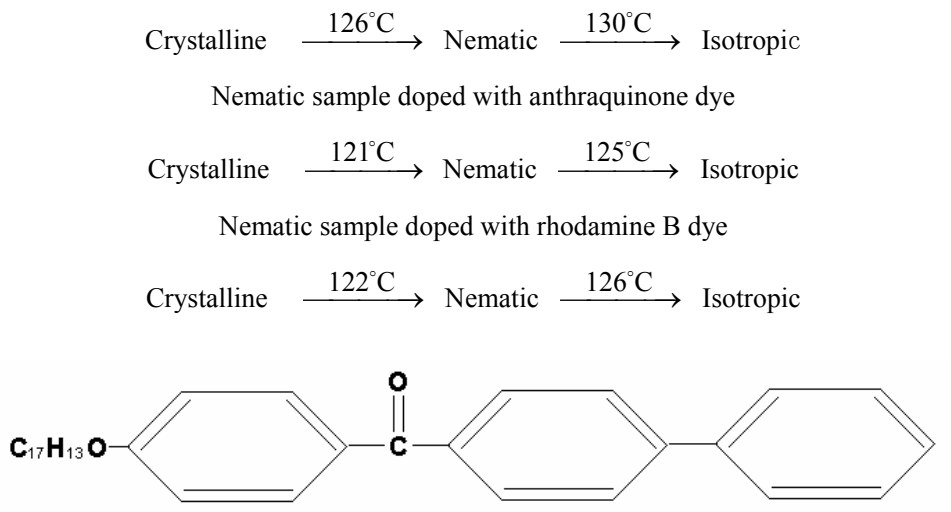

Figure 1. Structure of Nematic sample BKS/B07.

Anthraquinone Dye

1,5- Diamino-2(4-heptyloxy-phenyl)-4,8-dihydroxy-anthraquinone

CHEMICAL COMPOSITION: $\mathrm{C}_{27} \mathrm{H}_{23} \mathrm{~N}_{2} \mathrm{O}_{5}$<smiles>CCOc1ccc(-c2cc(O)c3c(c2N)C(=O)c2c(O)ccc(N)c2C3=O)cc1</smiles>

(a)

Rhodamine B Dye

N-[9-(2-Carboxyphenyl)-6-(diethylamino)-3H-xanthen-3-ylidene]$\mathrm{N}$-ethylethanaminium chloride CHEMICAL COMPOSITION: $\mathrm{C}_{28} \mathrm{H}_{31} \mathrm{ClN}_{2} \mathrm{O}_{3}$

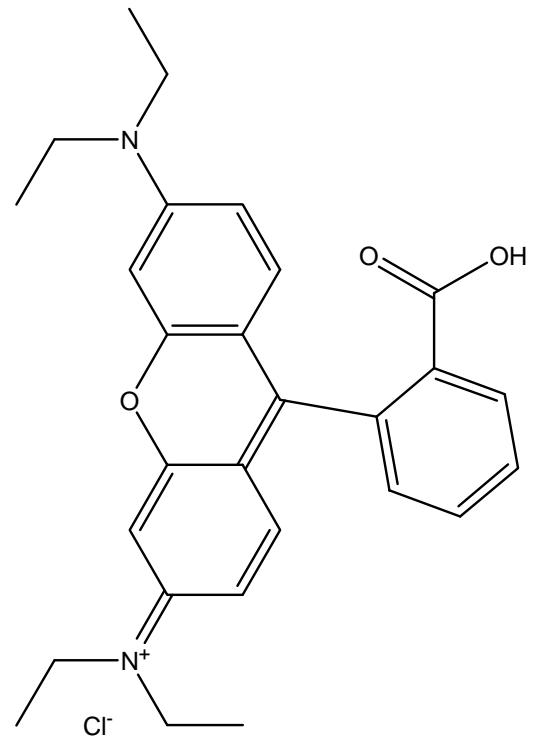

(b)

Figure 2. Structures of dyes used in present study. 

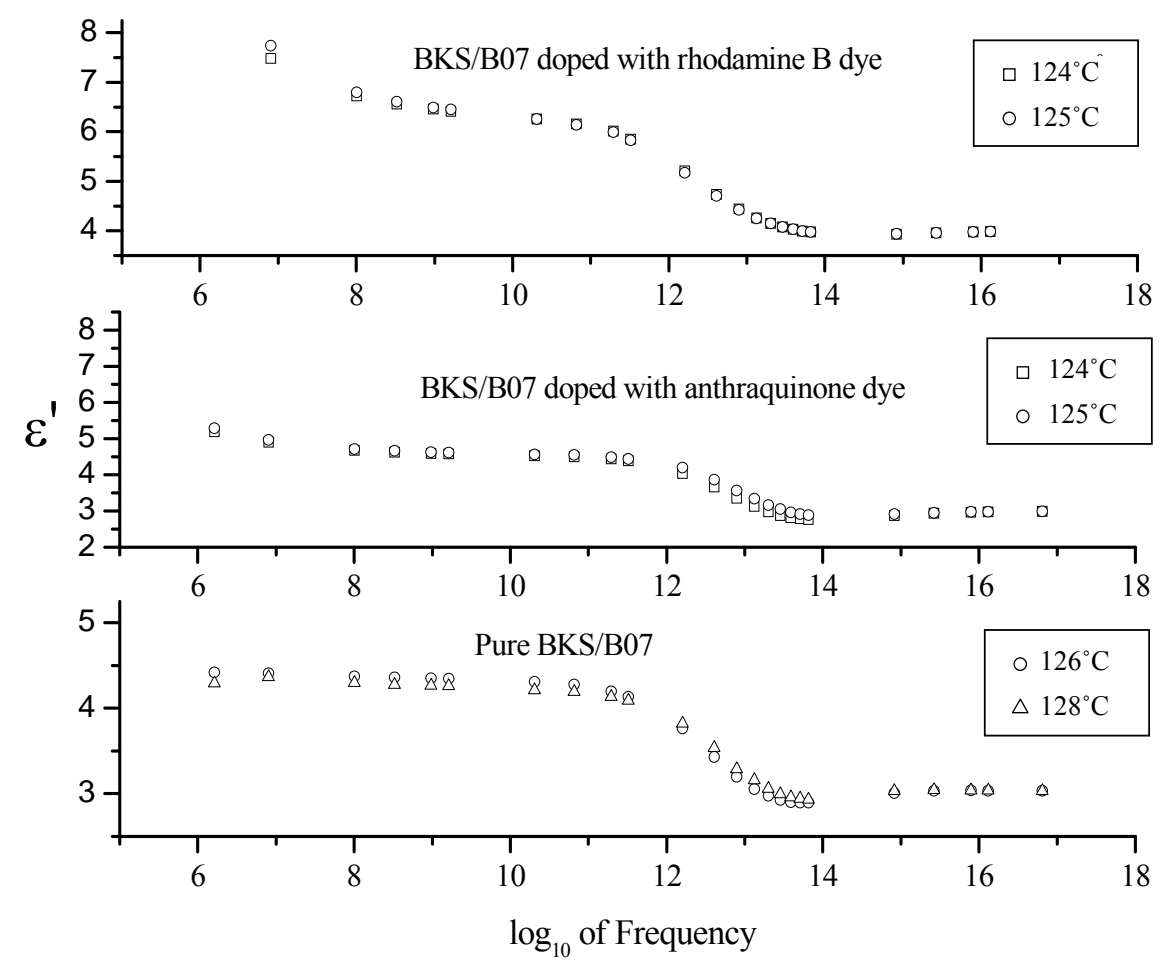

Figure 3. Variation of dielectric constant with $\log _{10}$ of frequency for pure nematic sample with two dyes (anthraquinone, rhodamine B)

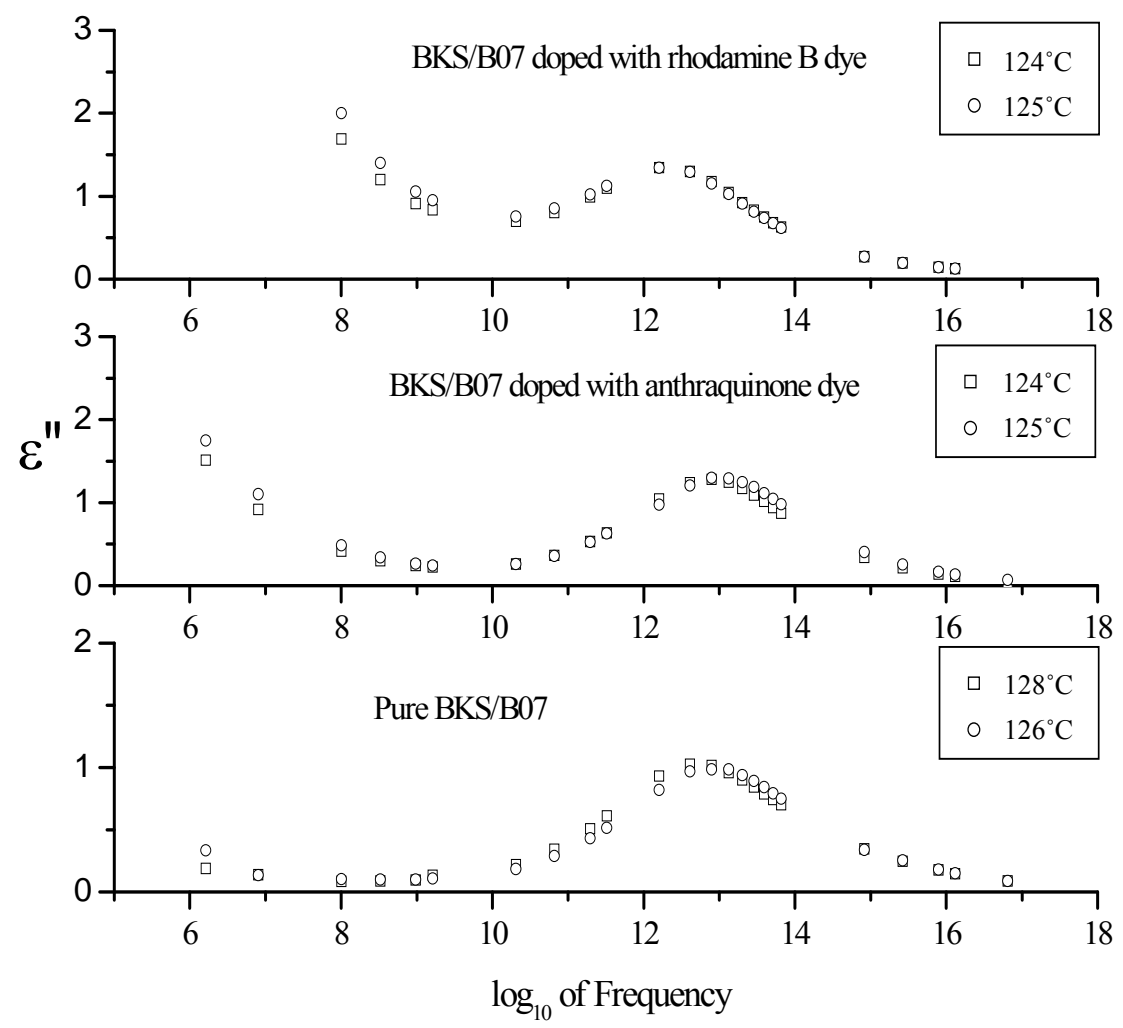

Figure 4. Variation of dielectric loss with $\log _{10}$ of frequency for pure nematic sample with two dyes (anthraquinone, rhodamine B). 
sample of BKS/B07 was prepared in the lab by dispersion of two dyes under investigation at a concentration of about $2 \% \mathrm{wt} / \mathrm{wt}$ in the liquid crystal host material. The strong interaction between two different types of molecules allow the samples to maintain a good alignment [16], which has been confirmed by observing at the sample holder under polarizing microscope. This guest-host mixture and pure sample were filled in a sandwich type sample holder having coating of Indium Tin Oxide (ITO) on the glass substrate and pre-treated with polyamide for planner type alignment. The temperature of the sample was controlled and maintained by a microprocessor based temperature controller Julabo (model no. F-25 HD) to an accuracy of $\pm 0.01^{\circ} \mathrm{C}$. The temperature of the sample holder on the double walled jacket was measured using an external Pt-100 type sensor. The sample cell was connected to Hewlett-Packard Impedance/Gain Phase Analyser (model HP 4194 A) working in the frequency range of $1 \mathrm{kHz}$ to $40 \mathrm{MHz}$. For obtaining the values of capacitance and dissipation factor, the sample holder was calibrated using AR grade benzene. The values of capacitance in the cell with sample and without sample were measured. The dielectric constant was obtained using the relation

$$
\varepsilon^{\prime}=\frac{\Delta C}{C_{G}}+1
$$

where $\Delta \mathrm{C}$ is change in capacitance of the sample holder with and without sample, which is

$$
\Delta C=C_{P}-C_{0}
$$

where $C_{P}$ is the capacitance of sample holder with sample and $C_{0}$ is the capacitance of sample holder without sample. $C_{G}$ is the geometrical capacitance of the sample holder.

For the measurement of dielectric loss, dissipation factor D was measured for the sample holder with and without sample. Thus, the loss tangent was obtained using the relation

$$
\tan \delta=\frac{C_{P} D_{P}-C_{O} D_{O}}{C_{P}-C_{O}}
$$

where $D_{P}$ and $D_{O}$ are the dissipation with and without sample respectively.

Dielectric loss was determined using relation

$$
\varepsilon^{\prime \prime}=\varepsilon^{\prime} \tan \delta
$$

For the measurement of optical transmittance, a precision research polarising microscope was used (model no. CENSICO 7626). The homogeneously aligned sample holder was placed on a hot stage which is a double walled chamber in which oil of required temperature was circulated. For variation of temperature, the same temperature controller Julabo (model no. F-25 HD) as used during dielectric measurements was again used. The hot stage was placed between cross polarisers in the polarising microscope. The aligned sample was placed between crossed polarisers and was heated and the emergent light at different temperature was made to incident on one of the eyepieces which is fitted with a light dependent resistance (LDR). Thus, the variation of emergent light varies the resistance of LDR, which directly provides us the optical transmittance in arbitrary units.

Textures (microphotographs) of the samples have also been taken using a polarising microscope which is fitted with a camera in one of its eye pieces.

\section{Results and Discussion}

The variation of real and imaginary parts of relative permittivity, that is dielectric constant $\left(\varepsilon^{\prime}\right)$ and dielectric loss $\left(\varepsilon^{\prime \prime}\right)$ for pure nematic sample BKS/B07 and two dye mixed samples with log of frequency are shown in Figures 3 and 4 respectively. The variation of real and imaginary parts of relative permittivity that is dielectric constant $\left(\varepsilon^{\prime}\right)$ and dielectric loss $\left(\varepsilon^{\prime \prime}\right)$ for pure nematic sample BKS/B07 and with two dyes anthraquinone (mixture 1) and rhodamine B (mixture 2) with temperature are shown in figures $\mathbf{5}$ and $\mathbf{6}$ respectively. Figure $\mathbf{7}$ shows the variation of percentage optical transmittance with temperature for pure nematic sample BKS/B07 and two dye mixed samples (mixture 1 and 2). Textures of the nematic sample BKS/B07 along with its two guest-host mixtures in crystalline and nematic phases have been presented in Figures 8 to 9.

The dielectric parameters $\varepsilon^{\prime}$ and $\varepsilon^{\prime \prime}$ have been measured for a nematic liquid crystal BKS/B07 in the frequency range of $1 \mathrm{kHz}$ to $10 \mathrm{MHz}$ for the temperature range of $70^{\circ} \mathrm{C}$ to $135^{\circ} \mathrm{C}$. Figure 3 and Figure 4 represent typical frequency dependence spectra of the real and imaginary part of the dielectric permittivity measured for nematic sample BKS/B07 and dye doped mixtures 1 and 2. The dielectric permittivity is found to be either constant or to decrease as the frequency increases [17-22] for pure sample. Lower values of $\varepsilon^{\prime}$ at higher frequency suggest that the molecules rotate about their long molecular axis [23]. The behaviour of $\varepsilon^{\prime}$ for the dye based mixtures 1 and 2 is similar to that of pure sample but the values of dielectric constants are higher in comparison to the corresponding values of pure sample.

One can see from the figure 4 that a maximum in the loss curve is observed at frequency $382 \mathrm{kHz}$ for the temperature $128^{\circ} \mathrm{C}$ for pure sample. The peak in the curve indicates dielectric relaxation and it shifts towards lower side of frequency as the temperature increases as expected and also reported by other workers [24,25].

The nature of loss curve again is similar to that for pure sample for other dye doped samples but it is evident 


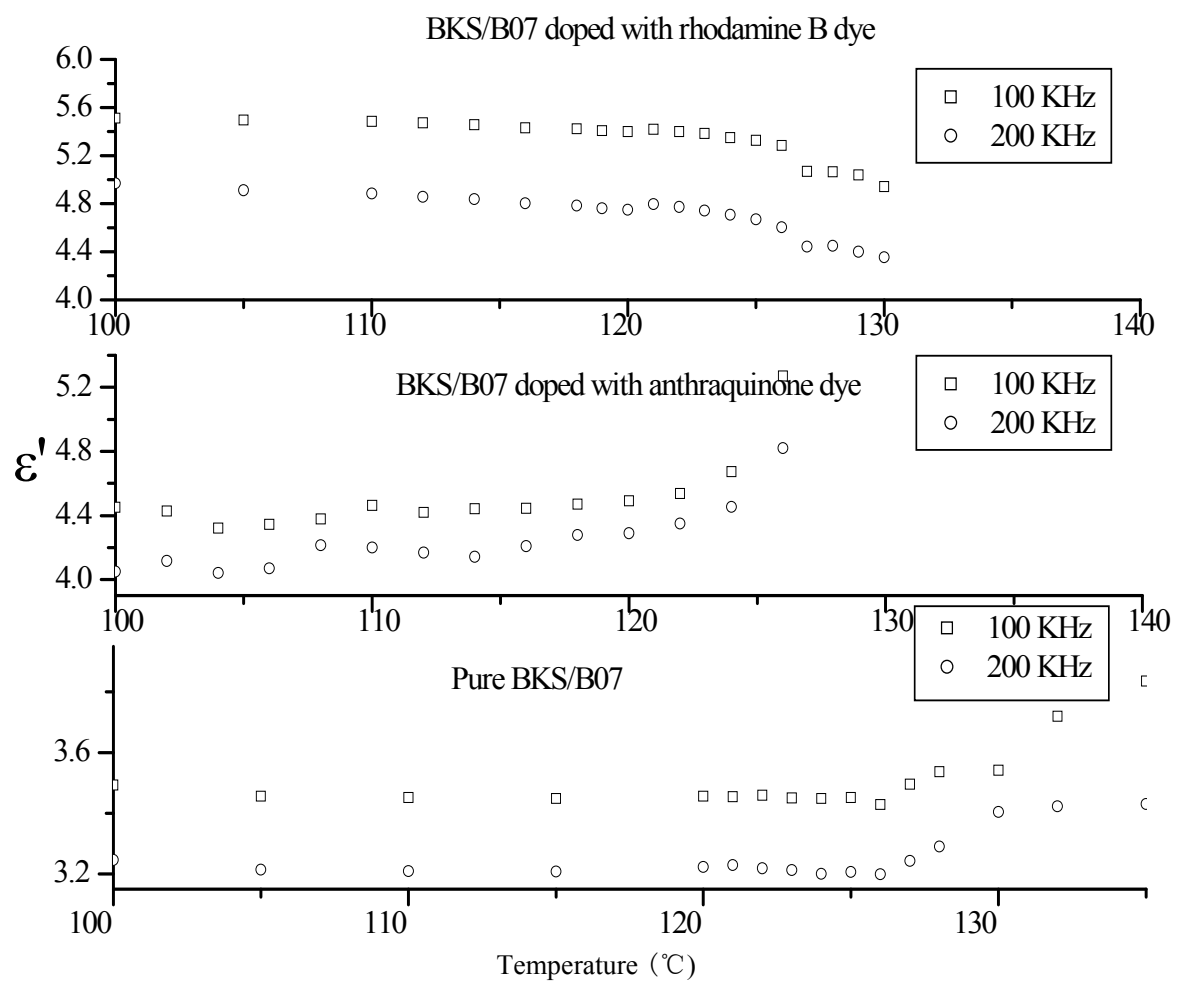

Figure 5. Variation of dielectric constant with temperature for pure nematic samplewith two dyes ( anthraquinone, rhodamine B).

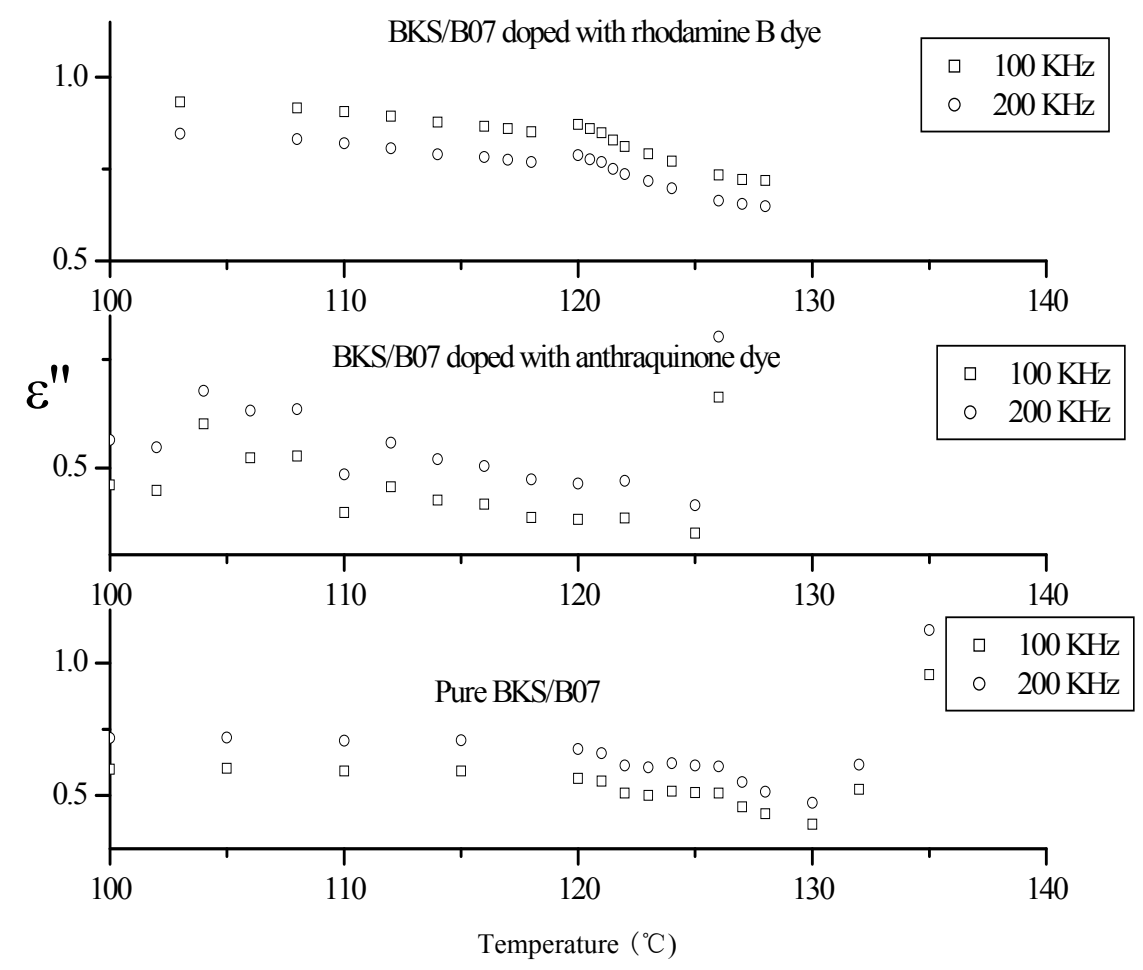

Figure 6. Variation of dielectric loss with temperature for pure nematic samplewith two dyes ( anthraquinone, rhodamine B) 


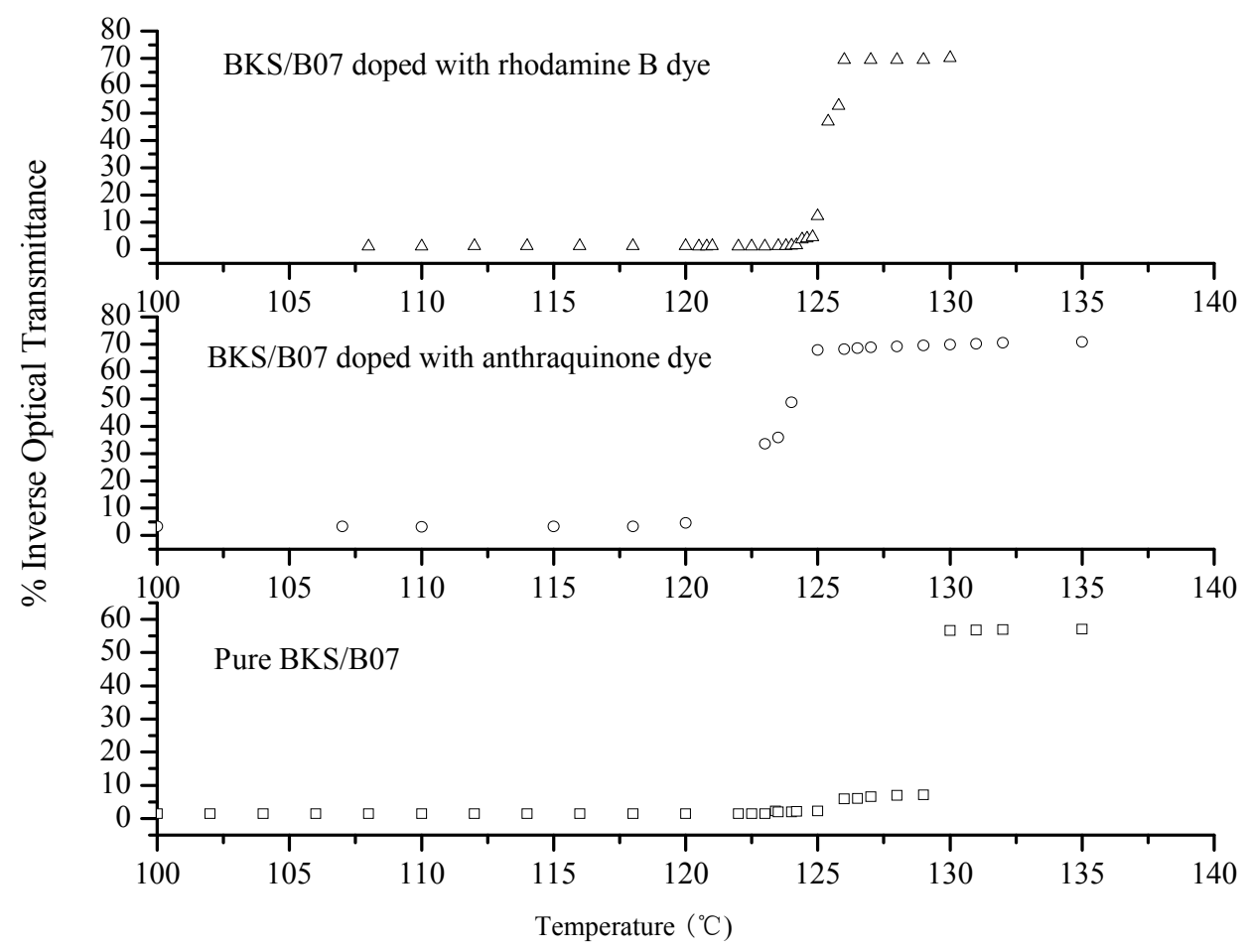

Figure 7. \% Inverse Optical transmittance Vs temperature for pure nematic samplealong with two dyes ( anthraquinone, rhodamine B).

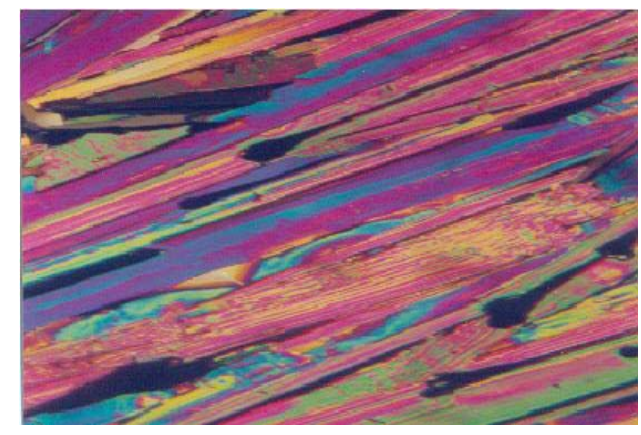

(a)

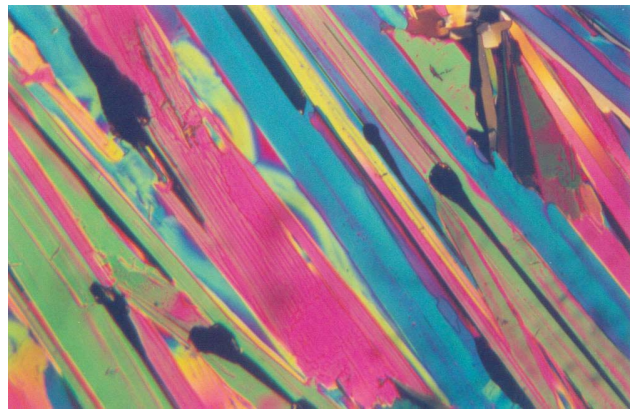

(b)

Figure 8. Texture of pure nematic sample BKS/B07 in (a) crystalline phase at $80^{\circ} \mathrm{C}$; (b) nematic phase at $127^{\circ} \mathrm{C}$.

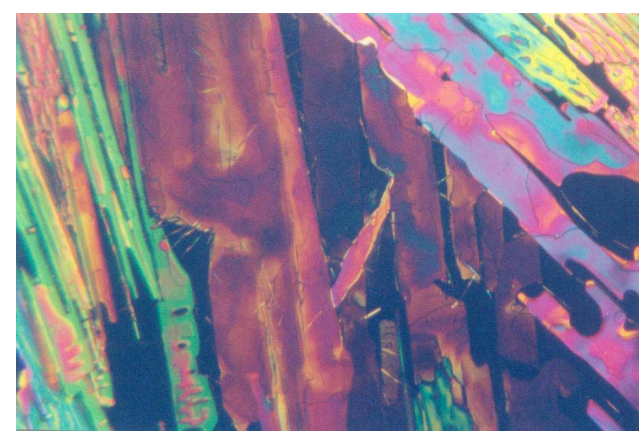

(a)

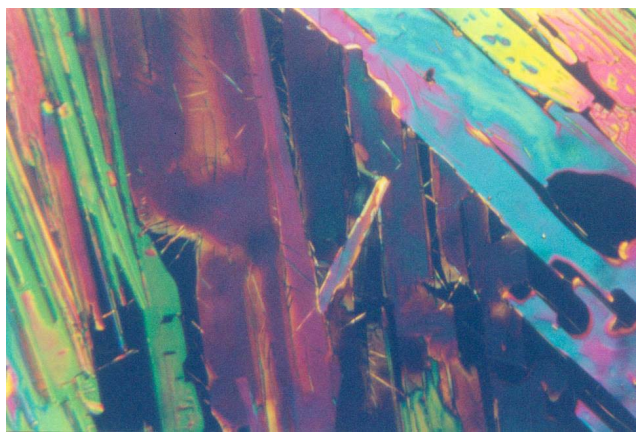

(b)

Figure 9. Texture of Pure nematic Sample BKS/B07 doped with anthraquinone dye in (a) crystalline phase at $80^{\circ} \mathrm{C}$; $(\mathrm{b})$ nematic phase at $123^{\circ} \mathrm{C}$. 


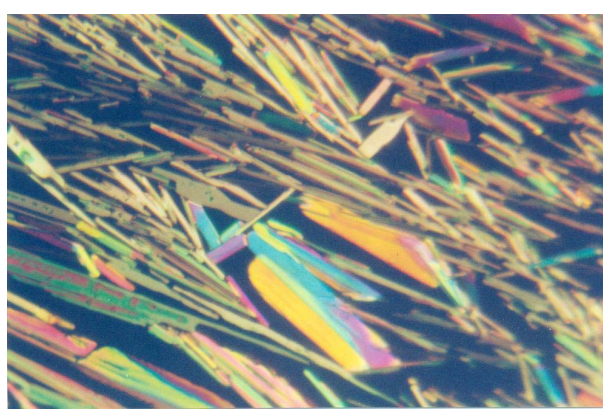

(a)

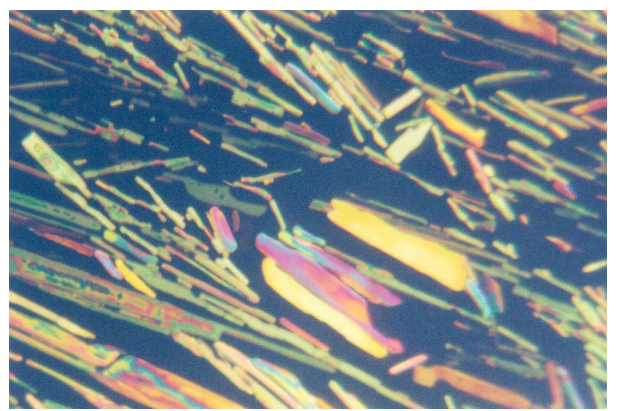

(b)

Figure 10. Texture of Pure nematic Sample BKS/B07 doped with rhodamine B dye in (a) crystalline phase at $80^{\circ} \mathrm{C}$;(b) nematic phase at $123^{\circ} \mathrm{C}$.

from the Figure 4 that the peak of the curve has been significantly shifted from the frequency of the peak obtained for pure sample. It suggests that the relaxation frequency of the dye doped mixture is different from that of pure sample and variation also depends upon the type of dye used and its compatibility with the liquid crystal host.

The variation in the value of $\varepsilon^{\prime}$ and $\varepsilon^{\prime \prime}$ due to addition of dye can be explained by considering the contribution of dipole moment of dye molecule in the host liquid crystal molecule. Each dye molecule has a preferential axis of orientation and it will get aligned along the host liquid crystal molecule thereby resulting in the restriction on the freedom of its movement. Thus, the dipole moment of dye molecule contributes significantly to the actual value of $\varepsilon^{\prime}$ and $\varepsilon^{\prime \prime}$ and also relaxation frequency value [26].

The Figures 5 and 6 show the variation of $\varepsilon^{\prime}$ and $\varepsilon^{\prime \prime}$ as a function of temperature for nematic sample BKS/B07 and for mixtures 1 and 2 . For the frequency range $1 \mathrm{kHz}$ $-10 \mathrm{MHz}$, the dielectric constant remains almost constant for the crystalline region and crystalline to nematic transition is detected by slight variation of dielectric constant at $126^{\circ} \mathrm{C}$ for nematic sample BKS/B07. It is interesting to note that a sharp peak appears near nematic to isotropic transition temperature at $130^{\circ} \mathrm{C}$ whose magnitude increases with decreases in the frequency. This type of variation has also been reported by other workers for other type of samples [24]. Similar types of variations have been noticed for the curves of $\varepsilon^{\prime \prime}$ versus temperature at varying frequencies shown in figure 6 . The hump at the nematic to isotropic phase transition temperature is more clear for lower frequencies.

The variation of $\varepsilon^{\prime}$ and $\varepsilon^{\prime \prime}$ with temperature for guest-host mixtures also have similar nature with a change that the transition temperature have shifted towards lower side by about $4^{\circ} \mathrm{C}$ to $5^{\circ} \mathrm{C}$ in comparison to the transition temperature for pure samples [26]. The transition temperature for mixture 1 are $121^{\circ} \mathrm{C}$ and $125^{\circ} \mathrm{C}$ for crystalline to nematic and nematic to isotropic transition. While for the mixture 2 the values of transition temperatures are $122^{\circ} \mathrm{C}$ and $126^{\circ} \mathrm{C}$ for the two transitions respectively. This decrease in the transition temperature is due to the fact that dye molecules behave as an impurity molecule in the liquid crystal host. The presence of impurity definitely decreases the transition temperature of the sample. It has been reported by our group [27] and various other researchers. Also the increased breadth of transition suggests that dye molecules behave as impurity in the liquid crystal matrix [28].

Figure 7 shows the variation of transmitted light through the sample in the terms of resistance of LDR under crossed polariser conditions. The percentage inverse optical transmittance decreases and the resistance increases for the two transitions i.e. crystalline to nematic and nematic to isotropic. It is obvious that the inverse optical transmittance remains almost constant in the crystalline region then it suddenly increases at $126^{\circ} \mathrm{C}$ indicating crystalline to nematic phase transition. It remains constant in nematic region and then again increases significantly by a large amount at $130^{\circ} \mathrm{C}$ indicating nematic to isotropic phase transition after which the value of transmittance again becomes almost constant with increase in temperature. This type of behaviour has been reported by our group [29] and by other workers for cholesteric as well as nematic liquid crystals [30]. For dye doped samples, the value of transition temperatures for nematic-isotropic transitions are $125^{\circ} \mathrm{C}$ and $126^{\circ} \mathrm{C}$ for mixture 1 and mixture 2 respectively while the crystalline to nematic transition is almost smooth as measured with the help of optical transmittance measurement technique. The absorption for two dye doped samples increases by a large amount, which is indicated by the higher values of the resistance of LDR in the isotropic region in comparison to the pure sample. However, the phase transition temperature for two guest-host mixtures measured using polarising microscope are not sharp as for the pure (single component) samples. It may be pos- 
sible that the dye molecules are behaving like impurity molecules for liquid crystal host. The breadth of the nematic-isotropic phase has also been observed by Demus et al. [31] and Singh et al. [32] for mixtures. It may be concluded that sharpness of the transition depends upon purity of the sample and it increases with the addition of different components because they behave like impurity with respect to each and that might be the reason for existence of bi-phase region. The phase transition temperatures as obtained by dielectric measurement technique and optical transition measurement technique are found to be very close to each other.

Textures (microphotographs) of pure sample and their guest host mixtures are shown in Figures 8(a, b), 9(a, b) and $10(\mathbf{a}, \mathbf{b})$ in crystalline and nematic phases. It may be seen that these textures also support our observations of the existence of different phases and identification of phase transitions [33-37].

\section{Conclusions}

It may be concluded that dielectric constant and dielectric loss values increase with the addition of dye and the relaxation frequency shift towards the lower or higher side depending upon nature, structure of dye and compatibility with the liquid crystal host. The transition temperature shifts towards lower side with the addition of dye because the guest molecule behaves like impurity for the pure sample. The absorption of light increases significantly due to presence of guest dye molecule in host liquid crystal molecule.

\section{ACKNOWLEDGEMENT}

Authors are thankful to Prof. B. K. Sadashiva of Raman Research Institute, Bangalore, India for providing the nematic sample. Authors are also thankful to ISRO for grant funds in the form of project.

\section{REFERENCES}

[1] K. Y. Wong, A. K.-Y. Jen, V. P. Rao and K. J. Drost, "Theoretical and Experimental Studies of the Molecular Second Order Nonlinear Optical Responses of Heteroaromatic Compounds," Journal Chemical Physical, Vol. 100, January 1994, pp. 6818-6825. doi:10.1063/1.467041

[2] D. Bauman and W. Haase, "Dielectric Measurements of Guest-Host Systems," Molecular Crystals Liquid Crystals, Vol. 168, August 1989, pp. 155-168.

[3] D. Bauman, "Comparative Studies of the Degree of Order of the Guest and Host Molecules in 4-Cyano-4'-n- Heptylp-Phenylcyclohexane (PCH7) Mixtures," Molecular Crystals Liquid Crystals, Vol. 174, March 1989, pp. 1-10. doi: $10.1080 / 00268948908042690$

[4] A. Jafari, H. Tajalli and A. Ghanadzadeh, "The Effects of External Applied Voltage on the Nonlinear Refractive Index and the Birefringence of a Dye-Doped Nematic
Mixture," Optics Communication, Vol. 266, No. 1, April 2006, pp. 207-213. doi:10.1016/j.optcom.2006.04.050

[5] F. Simoni and O. Francescangeli, "Effects of Light on Molecular Orientation of Liquid Crystals," Journal Physical Condensed Matter, Vol. 11, No. 41, October 1999, pp. 439-487. doi:10.1088/0953-8984/11/41/201

[6] J. Esteves and A. M. Figueiredo Neto, “Temperature Dependence of the Director Reorientation of Dye-Doped Nematic Liquid Crystals Subjected to an Optical Field And its Relation with the Non-Linear Absorption Coefficient," Liquid Crystals, Vol. 29, No. 5, May 2002, pp. 733-742. doi:10.1080/02678290210127760

[7] M. Voigt, M. Chambers and M. Grell, "Circularly Polarized Emission from a Narrow Bandwidth Dye Doped into a Chiral Nematic Liquid Crystal," Liquid Crystals, Vol. 29, No. 5, May 2002, pp. 653-656. doi:10.1080/02678290210126077

[8] J. F. Henniot, M. Dehailleul and M. Warenghem, "Tunable Non-locality of Thermal Non-linearity in Dye Doped Nematic Liquid Crystal," Molecular Crystals Liquid Crystals, Vol. 375, May 2002, pp. 631-640. doi:10.1080/10587250210613

[9] S. Sato and S. Fukudo, "Photovoltaic Effects in Liquid Crystal Cells Containing Organic Dyes," Molecular Crystals Liquid Crystals, Vol. 98, February 1983, pp. 99-108. doi:10.1080/00268948308073465

[10] M. Okutan, S. E. San, O. Koysal and F. Yakuphanoglu, "Investigation of Refractive Index Dispersion and Electrical Properties in Carbon Nano-Balls' Doped Nematic Liquid Crystals," Physica B, Vol. 362, No. 1-4, February 2005, pp. 180-186.

doi:10.1016/j.physb.2005.02.009

[11] H. Allinson and H. F. Gleesson, "Dielectric Permittivity Properties of a Fulgide Dye Guest-Host Liquid Crystal," Liquid Crystals, Vol. 19, No. 4, October 1995, pp. 421425. doi:10.1080/02678299508032002

[12] T. Grudniewski, J. Parka, R. Dabrowski, A. Januszko and A. Miniewicz, "Investigations of the Diffraction Efficiency in Dye Doped LC Cells under Low Frequency AC Voltage," Opto-Electron Reviews, Vol. 10, No. 1, January 2002, pp. 11-15.

[13] M. Okutan, F. Yakuphanoglu, S. E. San and O. Koysal, "Impedance Spectroscopy and Dielectric Anisotropy-Type Analysis in Dye-Doped Nematic Liquid Crystals Having Different Preliminary Orientations," Physica B, Vol. 368, No. 1-4, July 2005, pp. 308-317. doi:10.1016/j.physb.2005.07.029

[14] M. Okutan, S. E. San and O. Koysal, "Dielectric Spectroscopy Analysis of Molecular Reorientation in Dye Doped Nematic Liquid Crystals Having Different Preliminary Orientation," Dyes and Pigments, Vol. 65, No. 2, September 2005, pp. 169-174. doi:10.1016/j.dyepig.2004.08.001

[15] S. Ozder, M. Okutan, O. Koysal, H. Goktas and S. E. San, "Effect of an Azo Dye (DR1) on the Dielectric Parameters of a Nematic Liquid Crystal System," Physica B, Vol. 390, No. 1-2, July 2007, pp. 101-105. 
doi:10.1016/j.physb.2006.07.073

[16] W. M. Gibbons, P. J. Shannon, S. T. Sun and B. J. Swetlin, "Surface-Mediated Alignment of Nematic Liquid Crystals with Polarized Laser Light," Nature, Vol. 351, May 1991, pp. 49-50.

[17] A. Agrawal, V. P. Arora, R. V. Kaushik, P. P. Anand, K. Agarwal and B. Bahadur, "Dielectric Relaxation Mechanism in Liquid Crystalline Mixture ZLI 1840," Journal of Pure and Applied Physical, Vol. 27, 1989, pp. 299-301.

[18] A. M. Biradar, S. Hiller, S. A. Pikin and W. Haase, "Surface Molecular Relaxation in Smectic C* Phase as Studied by Dielectric Spectroscopy," Liquid Crystals, Vol.20, No. 2, October 1996, pp. 247-251. doi:10.1080/02678299608031132

[19] S. K. Kundu, K. Suzuki and B. K. Chaudhri, "Effect of Biasing Field on the Soft Mode in the Vicinity of the Smc ${ }^{*}$-Sma Phase Transition of a Ferroelectric Liquid Crystal ZLI 4851," Journal Applied Physical, Vol. 94, No. 4, August 2003, pp. 2271-2276. doi:10.1063/1.1587871

[20] H. J. Müller and S. JayaRaman, "Dielectric Properties of Nematic and Ferroelectric Liquid Crystals," Molecular Crystals Liquid Crystals, Vol. 309, January 1998, pp. 93-110.

[21] A. K. Thakur, D. K. Sharma, S. P. Singh, S. S. Bawa and A. M. Biradar, "Dielectric Relaxation near the Transition Temperature of Sm C*-Sm A Phase in Electroclinic Liquid Crystal," Ferroelectrics, Vol. 289, No. 1, January 2003, pp. 63-75. doi:10.1080/00150190390221160

[22] P. G. Cummins, D. A. Dunmur and D. A. Laidler, "The Dielectric Properties of Nematic 44'n-pentylcyanobipheny1," Molecular Crystals Liquid Crystals, Vol. 30, January 1975, pp. 109-123. doi:10.1080/15421407508082846

[23] A. M. Biradar, D. Kilian, S. Wrobel and W. Haase, "A Sub-Hertz Frequency Dielectric Relaxation Process in a Ferroelectric Liquid Crystal Material," Liquid Crystals, Vol. 27, No. 2, September 2000, pp. 225-231. doi:10.1080/026782900203029

[24] D. Bauman, J. Solczynski and E. Chrzumnicka, "Guest Effect on Nematic-Isotropic Phase Transition Temperature of Liquid Crystal 6CHBT," Liquid Crystals, Vol. 92, No. 6, August 1997, pp. 1155-1161.

[25] D. M. Potukuchi, A. George, C. Carboni, S. A. Harthi, J. Naciri, "Low Frequency Dielectric Relaxation, Spontaneous Polarization, Optical Tilt Angle and Response Time Investigations in a Flourinated Ferroelectric Liquid Crystal, N125F2(R*)," Ferroelectrics, Vol. 300, No. 1, January 2004, pp. 79-93. doi:10.1080/00150190490442245

[26] B. Bahadur, "Liquid Crystals-Application and Uses (vol-2)," World Scientific Publishing, NowYork, 1990.
[27] A. K. Srivastava, A. K. Mishra, P. B. Chand, R. Manohar and J. P. Shukla," Shifting of Transition Temperature of Ferroelectric Liquid Crystals Due to Addition of Dye-An optical and Dielectric Study," Journal of Physical Chemical Solid USA, Vol. 68, January 2007, pp. 523-529. doi:10.1016/i.jpcs.2007.01.010

[28] A. K. Singh, R. Manohar; J. P. Shukla and A. M. Biradar, "Refractive Indicies, Order Parameter and Optical Transmittance Studies of a Nematic Liquid Crystal Mixture," Acta Physica Polonica A, Vol. 110, No. 4, August 2006, pp. 485-496.

[29] R. Manohar, M. Gupta and J. P. Shukla, " Phase Transition Studies of Some Cholesteric Liquid Crystals and Their Mixtures Using Dielectric, Optical Transmittance and Density Measurement Studies" Journal of Pure and Applied Physical, Vol. 61, July 2000, pp. 1465-1473. doi:10.1016/S0022-3697(00)00014-7

[30] F. M. Gouda, "Dielectric Relaxation Spectroscopy of Chiral Smectic Liquid Crystals" Ph.D. Dissertation, Dept. of Physics, Chalmers University of Technology, Goteborg, Sweden, 1992.

[31] D. Demus, H. G. Hahn and F. Kuschel, "Density Measurements in Cholesteryl Myristate," Molecular Crystals Liquid Crystals, Vol. 44, January 1978, pp. 61-70.

[32] R. Singh, V. K. Agrawal, P. P. Anand and V. P. Arora, "Optical Behaviour of Nematic Mixture: 1975/S," Nature Academic Science Letters India, Vol. 13, No. 4, April 1990, pp. 129-131.

[33] M. B. Pandey, R. Dhar, V. K. Agarwal, R. Dabrowski and M. Tykarska, "Study of Different Modes of Dielectric Relaxation in a Newly Synthesized Material Exhibiting Ferro-, Ferri- and Antiferro-Electric Phases," Liquid Crystals, Vol. 31, No. 7, July 2004, pp. 973-987. doi:10.1080/02678290410001709275

[34] A. Sasaki, M. Inodo and T. Ishibashi, "Light Transmission and Texture Changes of Mixed Liquid Crystals by Temperature Variations," Molecular Crystals Liquid Crystals, Vol. 65, February 1981, pp. 39-49. doi: $10.1080 / 00268948108076129$

[35] E. G. Hanson and Y. R. Shen, "Refractive Indices and Optical Anisotropy of Homologous Liquid Crystals," Molecular Crystals Liquid Crystals, Vol. 36, March 1976, pp. 193-207. doi:10.1080/15421407608084323

[36] P. G. de Gennes, "The Physics of Liquid crystals," 3rd Edition, Clarendon Press, Oxford, 1974.

[37] S. Chandrasekhar, "Liquid Crystals," Cambridge University Press, Cambridge, 1977. 